MOTIVATIONAL FACTORS FOR CARING FOR PEOPLE LIVING WITH HIV IN SOUTH AFRICA: HOME-BASED CAREGIVERS EXPERIENCES

Robert Lekganyane

This qualitative study, based on Loretta Williams's middle-range theory of caregiving dynamics, explores and describes the motivations of home-based caregivers in caring for people living with HIV (PLHIV). Semi-structured interviews were conducted with twenty-five home-based caregivers from three provinces of South Africa. The study underscores Williams's theory. It revealed that caregivers are motivated by experiencing caregiving as a divine calling; a need for self-fulfilment; an innate passion; a response to personal experiences (having a sick family member, or who is HIV-infected); an alternative career (to nursing or social work); a form of employment; and utilising existing experiences and skills.

Dr Robert Lekganyane, Department of Social Work, UNISA, Pretoria, South Africa.

Robert Lekganyane, ORCID iD: 0000-0001-8434-7885

lekgamr@unisa.ac.za

Keywords: caring, caregiver experiences, motivational factors, HIV, home-based care, people living 



\title{
MOTIVATIONAL FACTORS FOR CARING FOR PEOPLE LIVING WITH HIV IN SOUTH AFRICA: HOME-BASED CAREGIVERS' EXPERIENCES
}

\author{
Robert Lekganyane
}

Dr Robert Lekganyane, Senior Lecturer, Department of Social Work, UNISA, Pretoria, South Africa.

\section{INTRODUCTION AND BACKGROUND}

Because of the challenges associated with HIV, interventions have been initiated worldwide to prevent the spread of the epidemic and mitigate its impacts. In Africa the establishment of home-based care (HBC) programmes became a widely adopted strategy to respond to the plight of HIV at community level (Lekganyane, 2016:121; Morton, Mayekiso, \& Cunningham, 2018:48). These programmes are mainly initiated by ordinary members of the community who are inspired by passion and concern for the health and welfare of PLHIV and their loved ones. Through these HBC programmes ordinary community members (mainly women) organise themselves to voluntarily render HBC services to PLHIV by, inter alia, visiting them at their homes to provide them with care and support services. Their services includes providing HIV preventive education to the public; assisting patients with practical matters, such as cleaning their houses, bathing and feeding them; following up on patients who are on antiretroviral (ARV) medicine and have missed their return dates; and providing counselling to patients and their family members (Moshi, 2017:7; Schneider, Hlophe \& Van Rensburg, 2008:183).

In rendering these services, caregivers encounter various difficulties (Kang'ethe, 2009:30; Kang'ethe, 2010:198; Ransom \& Asaki, 2013:381;). They often have to walk long distances to reach their patients and often lack adequate training and resources (Kangethe, 2010:197; Lund, 2010:502; Mokwele, 2016:7; Moshi, 2017:73; Ransom \& Asaki, 2013:382). By having to walk long distances through the neighbourhoods in order to reach their patients, caregivers expose themselves to criminal activities and extreme weather conditions without having the necessary resources to cope such as umbrellas or raincoats (Moshi, 2017:73; Valjee \& Van Dyk, 2014:10). They frequently experience severe emotional strain as a result of this emotionally demanding work (Ndaba-Mbatha \& Seloilwe, 2000:221). Their daily challenges of caring for PLHIV frequently expose them to experiencing a sense of inadequacy, helplessness, frustration and anger (Valjee \& Van Dyk, 2014:2). Caregiving is a taxing task, hardly taking into account the financial needs of the caregivers, if at all. In Kang'ethe's (2010:196) study of human rights perspectives on caring for PLHIV in Botswana, 80\% of the caregivers reported that they did not have any income to support themselves. In some instances, it is reported that caregivers who receive stipends may have to wait as long as six months before receiving the payments due to them (Moshi, 2017:49).

Mokwele (2016:5) argues that the effectiveness of care to PLHIV is determined by the level of support from the patient, the family and the community. Instead of receiving this support and appreciation, caregivers often have to face resistance, aggression criticism, stigma, active discrimination and violence from the patients, their families and the communities whom they serve (Kang'ethe, 2010:196; Mokwele, 2016:94; Moshi, 2017:51; Ramuhaheli \& Erasmus, 2012:24). Studies reveal that in some instances caregivers become frustrated by families who would chase them away and patients who would acknowledge their HIV infection one day, but later deny it because of fear of the stigma (Mokwele, 2016:94; Moshi, 2017:51; Ramuhaheli \& Erasmus, 2012:24). Caregivers also expressed their frustration with aggressive patients and families by highlighting their need for training on how to manage their relationships with patients and families as well as how to deal with aggressive patients (Mokwele, 2016:100 $\& 101)$.

Despite all these challenges, it is equally crucial to appreciate that all is not doom and gloom with regard to the conditions in which caregivers find themselves working. A South African study by Mokwele (2016:71) of the development and evaluation of a social work programme for community caregivers to facilitate HIV patients' adherence to antiretroviral treatment, for instance, revealed that caregivers are motivated by the community's appreciation of the valuable role which they play as a support system in the communities. The 
caregivers also reported that community members appreciated their work and consider them to be role models (Mokwele, 2016:95). In addition it is pointed out that some caregivers even go beyond the call of duty in caring for PLHIV (Akintola, Hlengwa \& Dageid, 2013:2739).

As much as it is crucial to appreciate the challenges and experiences faced by caregivers as highlighted above, it is equally important to comprehend the motivational factors for caregivers continuing to care for PLHIV. Understanding the factors that keep caregivers motivated to continue doing their work under these challenging conditions will ensure that programmes aimed at supporting the HBC programmes will achieve their aims. As described by some of the caregivers who participated in Mokwele's (2016:97) study, this motivation is a central requirement for the success of all these programmes. However, the author also revealed that caregivers experience challenges in relation to goal attainment and motivation. Yet according to Robinson (1998:771), very few studies have so far examined the motivational factors of caregivers who visit patients and care for them in their homes, although Mokwele (2016:249) pointed out that caregivers experience challenges in relation to goal attainment and motivation. This lack of research on the motivational factors for caregivers poses a threat to the HBC programmes because it means that these programmes, when they are being designed, are not adequately informed by research and the literature. In attempting to fill this research deficiency, a qualitative study was conducted to explore and describe the challenges experienced by caregivers and their motivations to care for PLHIV (Lekganyane, 2017). Based on Loretta Williams's (2007) wellknown middle-range theory of caregiving dynamics, this article presents the author's findings on the motivational factors for caregivers to continue caring for PLHIV (Lekganyane, 2017).

\section{THE MIDDLE-RANGE THEORY OF CAREGIVING DYNAMICS AND THE MOTIVATIONAL FACTORS FOR CAREGIVERS TO CARE FOR PLHIV}

The term 'middle-range theory of informal caregiving' was coined by Loretta Williams and primary purpose of the theory is to guide analysis of the positive forces that enhance the caregiving relationship between informal caregivers and their patients (Williams, 2014:310). It began as a concept called 'informal caregiving', which was used to describe the forces that stimulate and shape change and growth in the relationship between informal caregivers and their patients and later on developed into a middle-range theory (Garmon, 2019:25; Williams, 2014:310). Central to this theory is the fact that this caregiving is a relationship between the caregiver and the patient, and this relationship is a process through which certain dynamics such as commitment, expectation management, role negotiation, selfcare, new insight and role support come into play to move the relationship forward (Williams, 2007:379; Williams, 2014:311).

In terms of the theory, through involvement and commitment, the caregiver develops a determination to continue caring despite the duration of care. Caregivers in this instance somehow feel obliged to care because of their love of caring and this keeps them going (Eslami, Barekatain \& Zamani-Alavijeh, 2019:3; Goodhead \& McDonald, 2007:74; Williams, 2007:382; Williams, 2014:311; Zahed, Emami, Bazargan-Hejazi). They also place the needs of the patients before their own and become inspired by the objective to achieve the patient's wellbeing. In some instances this is done by simply demonstrating support through comforting and encouraging patients and maintaining a positive attitude in cases where there is nothing else to do to assist the patient (Williams, 2007:382; Williams, 2014:311). What inspires the caregiver here is the need to understand patients' experiences so that they can adequately respond to their emotional needs. A sense of emotional gratification emanating from satisfying the patients' needs also becomes one of the factors driving this relationship (Williams, 2007:382; Williams, 2014:311; Zahed, et al., 2019:5).

In terms of self-care, caregivers are inspired by the availability of support and their continued efforts to improve or maintain their own healthcare in order to ensure that they are always ready to fulfil the demands of caring (Williams, 2014:312). Through expectation management, the caregivers develop some sense of hope, which inspires them to continue caring (Williams, 2007:382; Williams, 2014:313). Here they believe that all the caring-related challenges will eventually come to an end sometime in the 
future and that things will be normalised. With this hope in mind, the caregivers manage these challenges by focusing more on the present experiences and not the future ones. They are inspired by their ability to use their prior knowledge and experience, which could be based on the history of their relationship with the patient in managing some of these challenges (Amendola, Oliveira \& Alvarenga, 2011:884; Williams, 2014:313).

Because as human beings caregivers have limitations and can intervene only up to a certain point, they also draw some inspiration by accepting that they are just human beings and not healers by coming to terms with the limitations of their interventions (Williams, 2014:313). With regard to new insights gained, caregivers are motivated by personal growth and the comfort which they find by leaning on the Lord. They are also inspired by seeing their caring efforts leading to positive change in their patients' lives (Williams, 2007:382; Williams, 2014:314). In addition, a sense of inspiration for caregivers is also found in role negotiation where they encourage patients to follow treatment schedules, see the patients grappling with their illness, and engage in collaborations and lobby for the patients' benefit (Williams, 2014:315). The mere knowledge that there are some people who care about and acknowledge the caregivers' contribution and their actual experience of such support is one of the drivers of their relationships with patients (Amendola et al. 2011:880; Goodhead \& McDonald, 2007:70; Williams, 2014:316). Caregivers become more positive when they are assured of assistance and support from other people (Goodhead \& McDonald, 2007:7). Their experiences of assistance and support in this instance involve receiving support to address their own financial needs and receiving useful information on how to continue rendering effective and efficient care.

\section{RESEARCH GOAL AND QUESTION}

The research goal and overall aim of this study was to develop an in-depth understanding of caregivers' experiences in relation to caring for PLHIV, their work-related challenges and the coping strategies they employ to address these challenges. The research findings reported through this article emanated from the following research question:

- What prompts and motivates home-based caregivers to care for PLHIV?

\section{RESEARCH METHOD}

This was a qualitative study, based on explorative, descriptive, contextual and phenomenological research designs. A qualitative research approach was chosen because of its suitability in studies that seek answers to questions aiming to address the experiences, meanings and perspectives of the participants (Aspers \& Corte, 2019:146; Hammarberg, Kirkman \& de Lacey, 2016:499). Among the categories of studies that are of interest to qualitative researchers are the social responses to the epidemics and the nature of health care in response to changing methods of diagnosis and treatment (Morse, 2020:2; Teti, Schatz \& Liebenberg, 2020:1). Human interactions such as the interaction between the caregiver and the patient during the caring trajectory (Aspers \& Corte, 2019:152) are central to qualitative research. This makes the qualitative research approach appropriate for this study.

\section{Research population and sampling}

Participants were identified and recruited from twelve HBC organisations in three of South Africa's provinces, namely Gauteng, North West and Limpopo. Approval for undertaking the study was obtained from the University of South Africa's Social Work Departmental Research and Ethics Committee as well as from the managers and caregivers of the HBC organisations. Twenty-five caregivers from 12 organisations were identified and recruited by means of purposive and snowball sampling techniques. To qualify for inclusion in this study, participants had to:

- be 18 years or older;

- have two or more years' experience of caring for PLHIV;

- render home-based care services to PLHIV under the auspices of a home-based care organisation; 
- be willing to sign an informed consent document; and

- be willing to be audio-recorded.

Participants' were between the ages of 23 and 58 years old, with caring experience from two years to 12 years, who were caring for PLHIV. Of the 25, only three were males and the rest (22) were females. The composition of the sample in terms of racial population groups were as follows: two participants were coloured, one was an Indian, one was white and the rest (21) were black. Educationally, the participants varied in terms of their qualifications. Fourteen were in possession of a matriculation certificate; in addition to matric certificates, two were in possession of post-matric qualifications (counselling and fire-fighting certificates respectively) and eight passed grades lower than matric. In terms of their incomes, participants' monthly earnings ranged from R500 to R5 200 in the form of social grants and stipends. Geographically three of the participants were recruited from HBC organisations which were located in the North-West Province, five were from Limpopo and 17 were from Gauteng. Table 1 provides a summary of the socio-demographic profiles of the participants.

\section{TABLE 1}

\section{THE SOCIO-DEMOGRAPHIC PROFILES OF THE PARTICIPANTS GROUPED ACCORDING TO THEIR PROVINCES}

\begin{tabular}{|c|c|c|c|c|c|c|c|}
\hline Pseudonym & Gender & $\begin{array}{l}\text { Population } \\
\text { group }\end{array}$ & Age & $\begin{array}{l}\text { Educational } \\
\text { qualification }\end{array}$ & Income & $\begin{array}{l}\text { Caring } \\
\text { experience }\end{array}$ & Province \\
\hline Ntombizodwa & Female & Black & 38 & Grade 12 & R3 780 & 2 years & Gauteng \\
\hline Ramaisela & Female & Black & 34 & Grade 12 & R2 680 & 12 years & Gauteng \\
\hline Dineo & Female & Black & 28 & Post-matric & R3 280 & 4 years & Gauteng \\
\hline Amelia & Female & Black & 31 & Grade 12 & R1 840 & 2 years & Gauteng \\
\hline Mankwana & Female & Black & 45 & Grade 9 & R500 & 2 years & Gauteng \\
\hline Mpshe & Female & Black & 39 & Grade 10 & R2 180 & 7 years & Gauteng \\
\hline Paul & Male & White & 45 & Grade 12 & R5 200 & 23 years & Gauteng \\
\hline Martin & Male & Black & 58 & Grade 12 & R800 & 3 years & Gauteng \\
\hline Mokete & Female & Black & 43 & Grade 12 & R5 180 & 7 years & Gauteng \\
\hline Wendy & Female & Black & 42 & Grade 12 & R1 500 & 12 years & Gauteng \\
\hline Selina & Female & Black & 58 & Grade 12 & R6 180 & 4 years & Gauteng \\
\hline Kgomo & Female & Black & 56 & Grade 12 & R1 500 & 10 years & Gauteng \\
\hline Segwagwa & Female & Black & 47 & Post-matric & R1 020 & 8 years & Gauteng \\
\hline Xhathula & Female & Black & 42 & Grade 12 & R2 180 & 3 years & Gauteng \\
\hline Pekwa & Female & Black & 45 & Grade 11 & R2 560 & 3 years & Gauteng \\
\hline Nomvula & Female & Black & 38 & Grade 9 & R3 360 & 5 years & Gauteng \\
\hline Ching & Female & Black & 38 & Grade 10 & R1 840 & 4 years & Gauteng \\
\hline Mamadee & Female & Black & 39 & Grade 12 & R2 000 & 2 years & Limpopo \\
\hline Zulu & Female & Black & 24 & Grade 12 & R2 680 & 8 years & Limpopo \\
\hline Cassie & Female & Black & 39 & Grade 10 & R2 280 & 7 years & Limpopo \\
\hline Vanessa & Female & Indian & 38 & Post-matric & R3 520 & 6 years & Limpopo \\
\hline Pekwa & Female & Black & 45 & Grade 12 & R2 560 & 3 years & Limpopo \\
\hline Viola & Female & Black & 27 & Grade 9 & R1 500 & 2 years & North-West \\
\hline Letsatsi & Female & Coloured & 38 & Grade 12 & R2 020 & 2 years & North-West \\
\hline Jini & Female & Coloured & 40 & Grade 11 & R1 500 & 10 years & North-West \\
\hline
\end{tabular}

The demographic particulars of the participants in this study showed some concurrence with that of other researchers. For example, in Kang'ethe's (2009:27) study in Botswana on the challenges affecting the quality of care rendered by home-based care programmes for persons living with HIV and other terminal illnesses in the town Kanye, only $2 \%$ of the caregivers were men. In a local study by Akintola et al. (2013:1242) all 126 caregivers were women and only three had a post-matric or higher educational qualification. 


\section{Data collection}

The primary method of data collection was conducting semi-structured interviews guided by an interview schedule. The interview schedule was developed on the basis of a systematic literature review and consisted of five questions, focusing on the motivation of caregivers to care for PLHIV; their experiences in caring for PLHIV; their work-related challenges; coping strategies; and the support required from social workers. To supplement the interviews, a diary was used to record some of the interaction patterns and other events observed during the data-collection process. The interviews lasted between 45 and 90 minutes.

\section{Data analysis and verification}

The collected data were analysed according to the classic eight steps of data analysis, as proposed by Tesch (in Creswell, 2014:198). In verifying the data, the researcher adopted Guba and Lincoln's qualitative data-verification strategies, namely credibility, transferability, dependability and confirmability (Elo, Kääriäinen, Kanste, Polkki, Utrainen \& Kyngas, 2014:3; Nowell, Norris, White \& Mouse, 2017:3). To ensure credibility, prolonged engagement, persistent observation, triangulation and peer debriefing, were adopted (Flick, 2018; Nowell et al., 2017:3).

Prolonged engagement and persistent observation involved the author spending a period of two weeks roaming around and exploring all research sites to become acquainted with their dynamics by carefully and patiently observing the participants and their circumstances during the interviews. Data triangulation involved using the observations and interviews to supplement the data, while peer debriefing was accomplished with the assistance of a colleague who was studying for his doctoral qualification using qualitative research (Nowell et al., 2017:4). Dependability and transferability were ensured through a thick description, which involved detailing the data records, field notes, transcripts and a reflexive journal (Barush, Gringeri \& George, 2011:13; Nowell et al., 2017:3; Tracy, 2012:842). A detailed motivation for the decisions to adopt the analytical, methodological and theoretical choices was provided consistently to enhance confirmability (Nowell, et al., 2017:3).

\section{FINDINGS ON THE MOTIVATIONAL FACTORS FOR HOME-BASED CAREGIVERS CARING FOR PEOPLE LIVING WITH HIV}

The findings of this research address the research question pertaining to the participants' motivations in caring for PLHIV. The findings are presented through the themes and subthemes that emerged from the analysis of data obtained from the participants during the interviews, complemented by a literature control.

The accounts of the participants relating to their motivational factors for caring for PLHIV were collected and analysed, giving rise to a total of seven themes and four subthemes. Two themes (Themes 4 and 5) were further filtered into two sub-themes each. An overview of these themes and subthemes is presented in Table 2, followed by a detailed discussion complemented by a literature control. 
TABLE 2

A SCHEMATIC PRESENTATION OF THEMES AND SUBTHEMES

\begin{tabular}{|c|c|c|}
\hline Themes & Subthemes & Description \\
\hline $\begin{array}{l}\text { Theme 1: Perceptions of caring } \\
\text { as heeding a divine calling. }\end{array}$ & & $\begin{array}{l}\text { The theme explains how participants } \\
\text { considered caring for PLHIV to be a calling } \\
\text { from God. They believed that through their } \\
\text { caring, they were somehow heeding this call. }\end{array}$ \\
\hline $\begin{array}{l}\text { Theme 2: The self-fulfilling } \\
\text { nature of caring as a } \\
\text { motivational factor for } \\
\text { caregivers. }\end{array}$ & & $\begin{array}{l}\text { Theme } 2 \text { explains how participants perceive } \\
\text { caring as a form of self-fulfilment. They } \\
\text { believed that through caring, they obtain some } \\
\text { sense of self-gratification. }\end{array}$ \\
\hline $\begin{array}{l}\text { Theme 3: The innate passion to } \\
\text { care for one another as a } \\
\text { motive to care for PLHIV }\end{array}$ & & $\begin{array}{l}\text { In terms of theme } 3 \text {, participants explained } \\
\text { their belief that human beings have an inborn } \\
\text { passion to care for one another. They believed } \\
\text { that by caring for PLHIV, they were executing } \\
\text { the innate mandate of their humanity to care for } \\
\text { one another. }\end{array}$ \\
\hline $\begin{array}{l}\text { Theme 4: Personal experiences } \\
\text { as a motivation for caregivers } \\
\text { to care for PLHIV }\end{array}$ & $\begin{array}{l}\text { Sub-theme } 4.1 \text { : Having a sick family } \\
\text { member as a motivation to care for } \\
\text { PLHIV } \\
\text { Sub-theme } 4.2 \text { : The caregivers' HIV- } \\
\text { positive status as a motivation }\end{array}$ & $\begin{array}{l}\text { Theme } 4 \text { explains how participants were } \\
\text { inspired by their own personal experiences to } \\
\text { care for others. These experiences included } \\
\text { either having a sick family member, or being } \\
\text { HIV-infected themselves. }\end{array}$ \\
\hline $\begin{array}{l}\text { Theme 5: Caregivers' } \\
\text { consideration of caring as an } \\
\text { alternative career }\end{array}$ & $\begin{array}{l}\text { Sub-theme 5.1: Caregivers' } \\
\text { consideration of HBC as an alternative } \\
\text { to a nursing career } \\
\text { Sub-theme } 5.2 \text { : Caregivers' } \\
\text { consideration of caring as an } \\
\text { alternative to a social work career }\end{array}$ & $\begin{array}{l}\text { In theme 5, participants explained their } \\
\text { consideration of caring as an alternative career. } \\
\text { They considered caring as a career alternative } \\
\text { for nursing and social work. }\end{array}$ \\
\hline $\begin{array}{l}\text { Theme 6: Caregivers' } \\
\text { consideration of } \mathrm{HBC} \text { as a } \\
\text { form of employment }\end{array}$ & & $\begin{array}{l}\text { In theme } 6 \text { caregivers reported their views } \\
\text { about } \mathrm{HBC} \text { as a form of employment. They } \\
\text { considered caring as a form of employment. }\end{array}$ \\
\hline $\begin{array}{l}\text { Theme 7: The need to utilise } \\
\text { experiences and skills gained } \\
\text { from prior training }\end{array}$ & & $\begin{array}{l}\text { Theme } 7 \text { reveals how participants felt } \\
\text { about the need to make use of their experiences } \\
\text { and skills gained from their previous training. }\end{array}$ \\
\hline
\end{tabular}

\section{Theme 1: Perceptions of caring as heeding a divine calling}

Some of the participants became involved in caring for PLHIV because, as they indicated, they believed it was a calling from God, in other words, because they have "a strong inner impulse toward a particular course of action especially when accompanied by conviction of divine influence" (MerriamWebster. 2020. Sv "calling"). Below are extracts from the interviews conducted with participants:

To me is a calling because I have been passionate to care for people regardless of whether they are orphans or any other person. Because then I got involved in caregiving until today. (Masilo)

I feel that I can fulfil my calling from God, to love other people....Because God says clearly in His word, love God and love your neighbours. (Dineo)

If you do not have passion you cannot cope because we encounter many challenges... this kind of job is not about education or anything else, it is about calling. (Ntombizodwa)

My husband was sick. Then I am [HIV-infected] and my husband is also [HIV-infected]. He picked up from a zero CD4 count and you can imagine how bad he was at that time. As I talk right now, he is a man. We are doing thirteen years now in marriage. I think my passion to care for people developed from there. At that time, I did not know anything about palliative care. However, I developed the strength and decided to throw myself into it [caring] because I thought it was a calling that God had for me. (Ramaisela) 
Associating the provision of care to PLHIV with a divine calling is not a new phenomenon (Sempane \& Masango, 2013). Therefore identifying this perception among some of the participants was not surprising. Actually, caring appears to be the very purpose of human existence (Jolley, 2011:7). According to Masango (2005:915), God gave both human beings and animals the special gift of caring. In other words, animals and humans are meant to care for one another. In further concretising this notion of humanity's inherently caring nature, the Bible urges Christians to treat others as they themselves would like to be treated (Matthew 7:12). The innate nature of caring is also tantamount to the principle of ubuntu, which is an inborn sense of humanness, encouraging the spirit of caring, community, harmony, spirituality, respect and responsiveness to one another (Ndlovu, 2016:23). The perception of caring as a divine calling, as portrayed by caregivers of PLHIV, was also found among home-based caregivers who participated in Akintola's (2010a:6) South African study of perceived rewards among volunteer caregivers of PLHIV. These caregivers also expressed their belief that God would help them to overcome their difficulties. In another South African study conducted in Bushbuckridge, which examined the factors influencing caregivers to stop providing such care, volunteer caregivers indicated that they continue to care for PLHIV because they believe that God will reward them (Usinga, 2012:32). Other studies about caring for PLHIV found that caregivers were mainly Christians who were heeding a religious calling (Akintola, 2010b:59; Rödlach, 2009:428).

\section{Theme 2: The self-fulfilling nature of caring as a motivational factor for caregivers}

Apart from perceiving their caring work as a divine calling, some participants mentioned selffulfilment resulting from caring as one of the motives for them to continue caring for PLHIV. A sense of self-fulfilment was highlighted as follows:

I chose this field because I like to help people. I feel happy when I am able to help those who are in need. I like to see people being fine just like me. (Amelia)

With regard to the self-fulfilling nature of caring for PLHIV, caring for ill patients such as PLHIV is described as an act of commitment of time and effort that comes at a high price, without any expectation of material benefits (Moshi, 2017:8). This reflects the view of other researchers who have studied the subject of home-based care for PLHIV. A Canadian study by Crook, Weir, Williams and Egdorf (2006) on the experiences and benefits of volunteering in community HIV organisations, for instance, revealed that caregivers develop self-esteem and self-actualisation, among other things, from caring for PLHIV. In considering the perceived rewards among volunteer caregivers of PLHIV in faithbased organisations, Akintola (2010a:5) found that caregivers appreciated the need for self-growth and the need to develop selflessness. This sense of selflessness called for by Akintola's participants was described in the work of Primo (2007:46), where caregivers felt compelled to give away their own lunches and/or donate money to their patients. Valjee and Van Dyk (2014:7) reported similar findings that caregivers felt a sense of personal accomplishment from making a difference in their patients' lives by caring.

\section{Theme 3: The innate passion to care for one another as a motive to care for PLHIV}

During the interviews, some participants explained how they were born with the passion to care as follows:

For me, I have realised that I was born with this passion of caring for patients. That is why now I have this passion. (Mankwana)

[I] am naturally passionate because especially we black people, I don't expect someone to care for my brother or my sister, I care for even white people. But why I deny my brother or my sister, my neighbour or my community, you see. (Selina)

The assertions made by participants in relation to their general passion resulting from their belief in caring as a divine calling and the sense of self-fulfilment they derive from it affirm what some of the literature has revealed. This inborn passion, which appeared to be one of the factors motivating participants to care, has been noted by other researchers. For instance, in a South African study by 
Mokoena (2014:47) on resilience among caregivers of PLHIV in a Gauteng hospice, the caregivers explained that as their caring developed, they developed a greater sense of selflessness. In another South African study by Cobbing, Chetty, Hanass-Hancock and Myezwa (2017:1262), aimed at exploring the caregivers' experiences of being involved in carrying out HIV interventions in KwaZuluNatal, the caregivers reported experiencing an improved sense of self-worth as one of the benefits that motivated them to continue to render home-based care services to PLHIV.

\section{Theme 4: Personal experiences as a motivation for caregivers to care for PLHIV}

The theme of personal experiences as a motive for caregivers to care for PLHIV manifested in two ways in this researcher's study. Firstly, personal experiences either emerged through participants' testimonies of having witnessed a sick family member whom they cared for being cared for by caregivers, or simply having witnessed a sick family member suffering the pain of a chronic or terminal illness. In the second instance, the personal experiences were detailed through the caregivers' own HIV-positive status, which they believed inspired them to care for other PLHIV.

\section{Subtheme 4.1: Having a sick family member as a motivation to care for PLHIV}

Participants explained how various members of their families were sick and as a result of such sicknesses, they were inspired and decided to become caregivers:

I met the caregivers from this organisation when they visit us because my mother was sick. When they knock, I had to welcome them, as I was excited for a change that would eventually leave my mother in a good health status. However, my mother was not willing to welcome them. She eventually opened up and allowed them to help her. That is when I taught myself about this illness until today. (Dineo)

For me it started when I was nursing my grandmother in 1998. So it happened that she fell sick, there was no one to look after her, and I was still in school by then. So I could see her lying there feeling pain, wetting herself and there was no one who could look after her during the day. Therefore, when I come back from school I was the one who would bath her and make sure that she is clean. It happened that she passed on and after her death I developed this interest in the conditions of those people who are sick while in their homes. I asked myself what is going on in the homes of those people because I could see some of them around. (Mpshe)

"The reason why I like to be a care worker is because we have HIV person and at home we didn't know for about 10 years, she didn't tell anyone ... we [only found] out when she gave birth ... and when we get there she kept quiet, they were twins I was holding one, she is was holding another one and they [referring to the clinic personnel] said: you know that HIV-infected children are not supposed to be given water, and when the nurse come to us I asked her if we lost or what because we hearing her talking about HIV-infected people, what's happening? The nurse asked if she didn't tell us that she is [HIV-infected] and she said that one of the twins may be [HIV-infected] and when we ask our sister she asks "Didn't you know?" We were shocked because I had a little information and my mom didn't know a thing, and then that's when I joined, I learned how we have to treat her. (Xhathula)

During that period, I had a grandfather who was very sick. He was in the last days of his life and was admitted in the hospital. I was too scared to even visit the hospitals but the day on which my grandfather died, I decided to visit him together with my mother ... in the hospital ... Once we left, around ten o'clock in the evening we received a call, which notified us that he passed away. Then passion for helping people started to grow. (Segwagwa)

The accounts of caregivers having had a sick family member that motivated them to continue caring for PLHIV are supported by Ransom and Asaki (2013:368). These authors report that in many cases the original reason for women to undertake the role of caring for PLHIV is that they had a friend or a family member living with HIV (Ransom \& Asaki, 2013:368). Sæberg (2009:27) reported similar findings in a South African study on the motivations and experiences of voluntary care workers. According to Rosenstock (in Akintola, 2010a:9) knowing someone close who has HIV, serves as a "cue to action" involving the motivation to change sexual behaviour within the community. Apparently, the 
caregivers' knowledge and continuous witnessing of a family member living with HIV appear to have motivated them to attempt to change sexual behaviour within their community by getting involved in caring for PLHIV. In this context, it is crucial to note that changing sexual behaviour through educational programmes is one of the caregivers' duties (Akintola, 2016:3; Ramathuba, Mashau \& Tugli, 2015:2).

\section{Subtheme 4.2: The caregivers' HIV-positive status as a motivation}

In some interviews caregivers explained how their own HIV-positive statuses, subsequent illnesses and recovery inspired them to care for others who are sick. They explained their inspirational experiences as follows:

So after being healed I prayed for God to help me so that I can help other people like the way I was also helped. (Pekwa)

You see I am [HIV-infected] and I do care, that is why I do like this work so that I can help other people like I have received help as well. (Nomvula)

Doing this job is helping me a great deal. I was diagnosed with HIV a while ago. I actually discovered my status when I was pregnant. I suffered from a lot of stress because I did not have the right information about this disease. When I came to Vaal water, I learnt a lot about HIV. I saw the HIV posters and I was convinced that I would qualify to work in this area. (Zulu)

Research evidence in the field of HBC for PLHIV confirms the participants' statements pertaining to their own HIV-positive status as a motivational factor to keep them involved in caring for PLHIV. For instance, in Akintola's (2010a:6) study of community responses to HIV, one of the caregivers explained how the loss of her husband to HIV and her own positive status inspired her to care. In another study focusing on caring for people living with HIV, Sæberg (2009:3) found that caregivers drew some strength from their own HIV-positive status.

\section{Theme 5: Caregivers' consideration of caring as an alternative career}

It emerged that some participants were motivated to care for PLHIV by viewing their caring job as an alternative to other professional work, such as social work and nursing.

\section{Subtheme 5.1: Caregivers' consideration of HBC as an alternative for a nursing career}

Caring for PLHIV was in some instances regarded as an alternative for nursing, which is a desired career for some caregivers. The mere fact that caring for PLHIV in this instance was closer to nursing motivated the caregivers to continue caring for PLHIV. This is how one of the participants shared her experiences about it:

I like working with people and it has been my dream to be a nurse from my childhood. That is why I am a care worker and I like to change people's lives like many people outside they don't have information about their health, when they are sick they don't do a thing about it, like if I'm not working here they won't listen to me when I'm trying to give them some information because they don't take me serious so when I'm working here is when I can change people's lives, I can be free to talk to them. (Ching)

The desire to become a nurse as seen in the above quotation appears to be another motivator for some caregivers to care for PLHIV. This subtheme finds support from Akintola (2010b:6), who examined the care of volunteer caregivers caring for PLHIV in faith-based organisations in KwaZulu-Natal. Here, caregivers indicated their need to remain true to their desire to become nurses as one of their motivations to care. A similar finding was made in Canada by Claxton-Oldfield, Jefferies, Fawcett and Wasylkiw (2004:79) in their study about the motivation for palliative care volunteers to care, that one of the twenty-two reasons given was the desire to become a nurse. In Sæberg's (2009:30) research, caregivers reported that, should they be given an opportunity, they would move on and work as professional nurses. 


\section{Subtheme 5.2: Caregivers' consideration of caring as an alternative to a social work career}

One of the participants explained that she remained in caregiving because it was her second career choice after social work and that she was personally benefiting from the lessons that she was learning from providing home-based care. This is what she said:

It was hurting me when I could not become a social worker but I found peace when I become a caregiver. I decided to resort to work with people through caregiving ... But working with people made me learn a lot as when you go to sleep you would sleep knowing that you have put a smile on someone. (Mamadee)

No evidence could be found in the literature in support of caregivers who were motivated to become caregivers with the goal of ultimately becoming social workers. The involvement of social workers and nurses in $\mathrm{HBC}$ was mentioned mainly through the supportive role of the programme in some literature (Ama, 2011:42).

\section{Theme 6: Caregivers' consideration of $\mathrm{HBC}$ as a form of employment}

The scarcity of employment opportunities in South Africa appears to have been one of the drivers for caregivers to continue caring for PLHIV, despite the harsh conditions of work and the challenges they experience in the course of their work. The participants made it clear that they were desperate to find employment. Participants were quite clear about their need for a job as the motive to care for PLHIV. This is what they said:

\section{I became a caregiver because I was desperate for a job. (Cassie)}

When I was at home, I then told myself that this is the time to stand up to go and look for work now ... I just went out ... So I then asked to see the manager and they allowed me and he interviewed me at the same time. He was asking me questions like where do you come from? Why did you leave the old age home? I told him everything and he then said you are employed but you are going to start by volunteering and I said is fine. (Mpshe)

The need for employment expressed by participants as a motive for them to provide care is corroborated in the literature, which shows that the high unemployment rate in South African townships and the need to avoid being idle were sometimes the motive for caregivers to care for PLHIV (Akintola, 2010b:58; Rödlach, 2009:429; Wringe, Cataldo, Stevenson \& Fakoya, 2010:51). In her South African study of the factors influencing the dropout of community home-based caregivers at Nhleko Home-based Care in Mpumalanga, Bushbuckridge, Usinga (2012:17) also found that caregivers used caregiving as a means to find permanent employment. Caregivers who participated in the study by Akintola et al. (2013:2739) on perceived stress and burnout among caregivers of PLHIV mentioned the need for employment as one of their reasons for becoming involved in home-based care for PLHIV.

\section{Theme 7: The need to utilise experiences and skills gained from prior training}

In some interviews it became clear that the knowledge and skills possessed by the participants contributed to their commitment in caring for PLHIV. They felt that rather than sitting at home and doing nothing, they would like to make use of the skills and knowledge acquired in their previous training to care for PLHIV. This is what they said:

I came as a student doing practical, they saw how I was a hard worker, and after finishing my practical they called me to come and be a reliever when their staff are on leave or when there are more patients ... I was generally ready for everything. (Letsatsi)

I joined a group volunteering at schools ... and then I decided I needed to do something else ... I went and did a care-worker course. I didn't know exactly what was the money or what were the hours and what did the job really entail, but I knew I wanted to do something, and because I had the money I could pay for it and then do it. ... And then I went and did the care worker course, and then at times they put me in a hospice in Pretoria ... And there we worked with old people; it wasn't just a hospice, it 
was also an old-age home. I worked with old people doing my practical. And in there it came to the HIV Unit ... I was not totally educated about it. (Vanesa).

I started working here in the year 2011 but before I could work here, I was a caregiver in a private hospital. I started from $X Y$ [Hospital name] hospital and then to XX [Hospital name] hospital where I was also working as a caregiver and from there that is when I come here to do fieldwork. (Nakedi)

When I look at other [HIV-infected] people, they struggle, they don't know information as I got an information so I thought about being a volunteer to help people to understand what is HIV ... I started to volunteer.(Viola)

I am grateful for this job. I trained for home-based care in 1998. I don't regret my decision to join this organization. I can also provide counselling for myself about my patients. (Zulu)

Regarding the participants' comments about being motivated or inspired by their prior training and experience to care for PLHIV, there appears to be very little direct evidence in the literature. Unlike the participants of this study, who reported feeling inspired and motivated by the prior training and experience they had acquired, the literature indicates that the skills acquired through training and the caring experience provided by the organisations concerned, appear to have inspired and motivated the caregivers to continue caring for PLHIV (Akintola, 2010a:6). Training was also reported to be a motive by participants who took part in Sæberg's study (2009:34), as they expressed their happiness upon being trained in $\mathrm{HBC}$, because it afforded them an opportunity to help the community.

\section{DISCUSSION}

This study created a platform for home-based caregivers to explain their motivation for caring for PLHIV. Through this study caregivers demonstrated that despite the challenges involved in caregiving such as a lack of resources, inadequate or complete lack of training and of support, they are never deterred from caring for PLHIV. The experiences reported by the participants in this study appear to be in sharp contrast with the view of researchers such as Solomons (2014:2) and Van Deventer (2017:5) that caregivers feel overwhelmed by the intensity of HIV to such an extent that they feel hopeless and even wish to give in. Clearly, the caregivers who participated in the current study were neither hopeless nor despairing. They perceived caring for PLHIV in a more positive light and appeared to be inspired in many ways to continue doing the good work of caring for PLHIV. The findings thus seem to reflect Williams's (2007:385; Williams, 2014:311) theory of informal caregiving, which generally holds that the caregiving relationship is inspired by various dynamics which keep enhancing the caregiving relationship and motivating the caregiver to continue with this relationship.

From the findings, it appears that the caregivers were inspired by various factors to remain committed to caring for PLHIV. As is evident from the above discussion, they tended to believe that caring is a divine calling from God, which they had to heed. The caregivers' belief in God reaffirms the informal theory of caregiving through the dynamic of new insight which is enhanced through, among other things, leaning on the Lord (Williams, 2014:314).

By continuing to care for PLHIV, the caregivers were heeding this call at the highest level. It also appeared from the participants' narratives, that this caring is a way to pursue self-fulfilment. A sense of self-fulfilment as held by the informal caregiving theory is a reflection of commitment which emerges out of the emotional gratification experienced by the caregiver as he or she effects a change in the patient's life (Williams, 2007:382; Williams, 2014:311). In affirming their commitment, home-based caregivers considered caring to be an inherent characteristic of human nature which is fully integrated or assimilated within their identity. According to Williams (2007:382), commitment to care can be enhanced by means of enduring responsibility reflected when caregivers feel that they are somehow obliged to care.

By caring for PLHIV, caregivers tend to gain recognition, which in turn makes them feel proud about themselves and thus enhances their sense of self-esteem. According to Williams (2007:385), caregivers 
appreciate the recognition that they receive from contributing to the situation and circumstances of patients through caregiving. A sense of personal growth on the part of the caregiver tends to develop from realising the positive improvements that they effect in the lives of their patients and out of knowing that there are some who care about and appreciate their contributions (Williams, 2014:314 \& 316). It also appears that depending on their circumstances, the caregivers are inspired to care for PLHIV because of their own personal experiences, such as being infected with HIV themselves or having cared for a family member living with HIV. In some instances, the personal experiences involved witnessing an HIV-infected family member's suffering and the pain that this caused within their family/household.

The above views are some of the central elements of Williams's (2014:314) informal theory of caregiving. Along these lines, caregivers' prior training and experience in performing voluntary work served as a motivation to continue caring for PLHIV. Rather than idly sitting around at home, they preferred to use the skills and knowledge they had acquired through prior training and experience in voluntary work to benefit the community, specifically by caring for PLHIV. By so doing, they felt that they could be counted among those who are helping these suffering helpless persons. According to Williams (2014:311), when the caregiver and the patient enter into a caring relationship, they are also inspired by their past experiences, strengths and weaknesses, which somehow influences their relationship. It is therefore not surprising that in the context of this study caregivers made reference to their past experiences either in caring for someone who was living with HIV, or themselves having gone through the pain of living with HIV as an inspiration for them to care. As noted by Williams (2014:313), these past experiences enhance the informal caregiving dynamic of expectation management, since it allows caregivers to explain, predict or react to a patients' behaviours or experiences based on their prior experiences. In other words, in their caring the caregiver will either draw from their personal experience or from their training to determine the appropriate ways of intervention.

For some of the participating caregivers, caring for PLHIV was a form of employment from which they hoped to earn an income in order to survive their socioeconomic hardships. This element of the rationale to care reflects the dynamics of role support which holds that caregivers engage in caring because they receive some form of support with which to address their financial obligations (Williams, 2014:317). During the interviews it also emerged that some of the caregivers actually wanted to pursue a career in nursing or social work, but that their failure to meet the admission requirements for these qualifications prompted them to consider caregiving as an alternative career similar to those caring professions. In this instance, caring for PLHIV was found to be an appropriate alternative career to nursing and social work. Human beings strive to form relationships and to belong to certain groups and associations (Over, 2016:1). Consequently, the caregivers' desire to belong to one of the two aforementioned caring professions led them to the home-based care programme as a substitute and as a way of closely associating with the nursing or social work professions.

\section{RECOMMENDATIONS}

In studying the motivational factors for home-based caregivers' caring for people living with HIV, the findings of the study prompted suggestions to be made for ways in which the HBC programmes and the conditions of home-based caregivers can be improved from the perspectives of practice, training and research. Given the plight of PLHIV, the need to retain caregivers for these people remains critical. This requires various support-oriented retention interventions that respond directly to the caregivers' needs. Consequently, the following recommendations are proposed:

- HBC programmes should include wellness programmes that address the following aspects:

- religious or spiritual activities aimed at enhancing caregivers' religious beliefs, either on a oneon-one basis or in the form of a group within the HBC field; 
- individual or group programmes designed and implemented to enhance the caregivers' sense of identity, in view of their unique desire to achieve a sense of self-fulfilment through caring for PLHIV;

- family support programmes designed and implemented to support family members as caregivers of PLHIV; and

- continuous training and development programmes (CPDs) for caregivers to help them to remain up-to-date and equipped to respond to any of the issues experienced by their patients;

- Structures should be designed and developed to regulate and support the caregivers by, among other things, regulating and promoting their career development through continuous training.

\section{CONCLUSION}

In an attempt to contribute to a comprehensive understanding of the field of HBC for PLHIV, the motives for caregivers to continue caring for PLHIV were scrutinised in this study. The study has demonstrated that the home-based caregivers who are caring for PLHIV are not discouraged by the challenges associated with caring for these people. Despite the harsh conditions that come with their jobs, the caregivers appeared to be motivated by the following seven main factors to remain committed to this this form of service rendering:

- They perceive caring for PLHIV as a divine calling, which they have to heed. Hence, they felt morally obliged to remain committed to this course;

- They believe that human beings are born with the inherent natural desire to care for others. Therefore, by caring for PLHIV, they are fulfilling this natural desire;

- A sense of self-fulfilment, which emanates out of making a difference in the patients' lives, is regarded as a motivational factor driving caregivers to continue caring;

- Their personal experiences relating to HIV are noted as a motivation that kept them committed to the course of caring for PLHIV. Having sick family members or being HIV-infected themselves enhanced their passion and taught them some lessons which they utilise in their caring relationships with others;

- Their perception of HBC as an alternative career to social work and nursing is a motivational factor inspiring caregivers to care. Originally, some of them wanted to become either a social worker or a nurse, but did not meet the admission requirements to obtain the qualifications for these professions. As a result, they became involved with caring for PLHIV as an alternative career;

- Caregivers are motivated by their perception of caring for PLHIV as a form of employment and thus a means of gaining an income;

- Caregivers' previous training and/or work experience in caregiving acted as a source of motivation for them to continue to care for PLHIV. They felt that the skills, knowledge and experiences they had acquired previously can be utilised optimally to the benefit of PLHIV.

In this analysis of the motivations of home-based caregivers for caring for people living with HIV, the views expressed and the experiences shared by the participants were all found to clearly underscore and emphasise the dynamics of the informal theory of caregiving set out by Williams $(2007 ; 2014)$.

\section{REFERENCES}

AKINTOLA, O. 2010a. Perceptions of rewards among volunteer caregivers of people living with AIDS working in faith-based organisations in South Africa. A qualitative study. Journal of International AIDS Society, 13(22):1-10. 
AKINTOLA, O. 2010b. What motivates people to volunteer? The case of volunteer AIDS caregivers in faith-based organisations in KwaZulu-Natal, South Africa. Health Policy \& Planning, 2011(26):5362.

AKINTOLA, O. 2016. Factors influencing motivation and job satisfaction among supervisors of community health workers in marginalized communities in South Africa. Human Resource for Health, (14(54):1-15.

AKINTOLA, O., HLENGWA, W.M. \& DAGEID, W. 2013. Perceived stress and burnout among volunteer caregivers working in AIDS care in South Africa. Journal of Advanced Nursing, 69(12):2738-2749.

AMA, N.O. 2011. Experiences and perceptions of people living with HIV and AIDS under the community home-based care programme in Botswana. Journal of Family Life Welfare, 57(1):34-44.

AMENDOLA, F. OLIVEIRA, M.A.C., \& ALVARENGA, M.R.M. 2011. Influence of social support on the quality of life of family caregivers while caring for people with dependence. Journal of School of Nursing University of Săo Paulo, 45(4):880-885.

ASPERS, P. \& CORTE, U. 2019. What is qualitative research. Qualitative Sociology, 2019(42):139160.

BARUSH, A., GRINGERI, C. \& GEORGE, M. 2011. Rigor in qualitative social work research. A review of strategies used in published articles. Social Work, 35(1):11-19.

CLAXTON-OLDFIELD, S., JEFFERIES, J., FAWCETT, C. \& WASYLKIW, L. 2004. Palliative care volunteers: Why they do it? Journal of Palliative Care, 20(2):78-84.

COBBING, S., CHETTY, V., HANASS-HANCOCK, J. \& MYEZWA, H. 2017. "Knowing I can be helpful makes me feel good inside, it makes me feel essential". Community health care workers' experiences of conducting a home-based rehabilitation intervention for people living with HIV in KwaZulu-Natal, South Africa. AIDS Care, 29(10):1260-1264.

CRESWELL, J.W. 2014. Research design. Los Angeles: SAGE.

CROOK, J., WEIR, R., WILLIAMS, D. \& EGDORF, T. 2006. Experiences and benefits of volunteering in a community AIDS organisation. Journal of the Association of Nurses in AIDS Care, 17(4):39-45.

ELO, S., KäÄRIÄINEN, M., KANSTE, O., POLKKI, T., UTRAINEN, K. \& KYNGAS, H. 2014. Qualitative content analysis: a focus on trustworthiness. Sage Open, 1(4):1-10.

FLICK, U. 2018. Triangulation, in Denzin, N.K \& Lincoln, Y.S. (eds). The Sage handbook of qualitative research. London: Sage.:444-461.

GARMON, C. 2019. A multi-component education, skill and resource evidence-based practice intervention for the Alzheimer's caregiver. Texas: University of Texas at Taylor. (PhD thesis)

GOODHEAD, A. \& MCDONALD, J. 2007. Informal caregivers literature review: a report prepared for the national health committee. [Online] Available: https://www.moh.govt.nz/notebook/nbbooks.nsf/0/fb327285c9043995cc25734500069193/\$FILE/infor mal-caregivers-literature-review.pdf (Accessed: 04/05/2020).

HAMMARBERG, K., KIRKMAN, M. \& DE LACEY, S. 2016. Qualitative research methods: When to use them and how to judge them. Human Reproduction, 31(3):498-501.

JOLLEY, D.R.. 2011. Ubuntu: A person is a person through other persons. Cedar: Southern Utah University. (M dissertation) 
KANG'ETHE, S. 2009. Challenges impacting on the quality of care to persons living with HIV/AIDS and other terminal illnesses with reference to Kanye community home-based care programmes. Journal of Social Aspects of HIV/AIDS, 6(1):24-32.

KANG'ETHE, S. 2010. Human rights perspectives on caregiving of people living with HIV: The case for the Kanye home-based care programme, Botswana. Journal of AIDS Research, 9(2):193-203.

LEKGANYANE, M.R. 2016. HIV and AIDS-related courtesy stigma: South African caregivers' experiences and coping strategies. Alternation, 23(2):120-140.

LEKGANYANE M.R. 2017. Experiencing and managing work-related challenges by home-based caregivers caring for people living with HIV and AIDS: Guidelines for support from a social work perspective. Pretoria: Unisa. (PhD thesis)

LUND, F. 2010. Hierarchies of care work in South Africa: nurses, social workers and home-based care workers. International Labour Review, 149(4):495-509.

MASANGO, M. 2005. The African concept of caring for life. Health Systems Trust, 61(3):915-925.

MERRIAM-WEBSTER.COM DICTIONARY. 2020. Sv “calling". [Online] Available:

https://www.merriam-webster.com/dictionary/calling. (Accessed: 17/05/2020).

MATTHEW 7:8, Holy Bible: New International Version.

MOKOENA, R. 2014. Resilience of caregivers at a Gauteng hospice with people living with HIV/AIDS. Pretoria: University of South Africa. (M dissertation)

MOKWELE, R.M. 2016. The development and evaluation of a social work programme for community caregivers to facilitate HIV and AIDS patients' adherence to antiretroviral treatment. Potchefstroom: North-West University. ( $\mathrm{PhD}$ thesis)

MORSE, J. 2020. The changing face of qualitative inquiry. International Journal of Qualitative Research Methods, (19(1):1-7.

MORTON, D., MAYEKISO, T. \& CUNNINGHAM, P. 2018. Structural barriers to South African volunteer home-based caregivers providing quality care: the need for a policy for caregivers not affiliated to primary health care clinics. African Journal of AIDS Research, 17(1):47-53.

MOSHI, C. 2017. Evaluation of community home-based care programmes in the Capricorn District Municipality. Johannesburg: University of Witwatersrand. (M Dissertation)

NDABA-MBATHA, R.D. \& SELOILWE, E.S. 2000. Home based care of the terminally ill in Botswana: Knowledge and perceptions. International Nursing Review, 47(4):218-223.

NDLOVU, P.M. 2016. Discovering the spirit of ubuntu leadership, compassion, community and respect. London: Palgrave Macmillan.

NOWELL, L.S., NORRIS, L.S., WHITE, D.E. \& MOUSE, N.J. 2017. Thematic analysis: Striving to meet trustworthiness criteria. International Journal of Qualitative Methods, 16(1):1-13.

OVER, H. 2016. The origins of belonging: social motivation in infants and young children. Philosophical Transitions B, 371(1686):2-8.

PRIMO, M.W. 2007. Caring for the caregiver in HIV and AIDS programmes. Pretoria: University of South Africa. (M dissertation)

RAMATHUBA, D.U., MASHAU, N.S. \& TUGLI, A. 2015. Home-based carers' perceptions of health promotion on sexual health communication in Vhembe district. Curationis, (38(1):1-7.

RAMUHAHELI, R.M. \& ERASMUS, C.J. 2012. Challenges experienced while providing home-based care: A community organisation's experience. Journal of Community and Health Sciences, 7(1):2127. 
RANSOM, P.E. \& ASAKI, R. 2013. Home-based caregivers in Africa: Alliance building, advocacy and policy environments. Journal of Health and Human Services Administration, 36(3):367-391.

ROBINSON, N. 1998. People with AIDS: who cares? Journal of Advanced Nursing, 28(4):771-778.

RÖDLACH, A. 2009. Home-based care for people living with AIDS in Zimbabwe: Voluntary caregivers' motivations and concerns. African Journal of AIDS Research, 8(4):423-431.

SÆBERG, T. 2009. Caring for people with HIV/AIDS, a qualitative study of motivations and experiences of voluntary care workers in South Africa. Oslo: University of Oslo. (M dissertation)

SCHNEIDER, H., HLOPHE, H. \& VAN RENSBURG, D. 2008. Community health workers and the response to HIV/AIDS in South Africa: tensions and prospects. Health Policy and Planning, 23(3):179-187.

SEMPANE, L.J. \& MASANGO, M.J., 2013, 'Caring for the carer in the era of HIV diagnosis'. HTS Teologiese Studies/Theological Studies, 69(2):1-5.

SOLOMONS, D.P. 2014. Compassion fatigue: Pastoral care to HIV and AIDS caregivers within the realm of the healing professions. Stellenbosch: Stellenbosch University. (M dissertation)

TRACY, S.J. 2012. Qualitative quality: eight "big-tent" criteria for excellent qualitative research. Qualitative Inquiry, 16(10):831-851.

TETI, M., SCHATZ, E. \& LIEBENBERG, L. 2020. Methods in the time of COVID-19: the vital role of qualitative inquiries. International Journal of Qualitative Methods, 19(1):1-5.

USINGA, B.G. 2012. Factors influencing the dropping out of volunteer workers at Nhlengelo home-based care. Stellenbosch: Stellenbosch University. (M Dissertation)

VALJEE, L. \& VAN DYK, A.C. 2014. Impact of caring for people living with HIV on the psychosocial well-being of palliative caregivers. Curationis, 37(1):1-13.

VAN DEVENTER, C. 2017. The psychosocial impact of caregiving on the family caregivers of chronically ill AIDS and/or HIV patients in home-based care: A qualitative study in Zimbabwe. Southern African Journal of HIV Medicine, 18(1): 1-7.

WILLIAMS, L.A. 2007. Whatever it takes: Informal caregiving dynamics in blood and marrow transplantation. Oncology Nursing Forum, 34(2): 379-387.

WILLIAMS, L.A. 2014. Theory of caregiving dynamics. In: SMITH, J. \& LIEHR, P.A. (eds). Middle range theory for nursing. New York: Springer: 309-328.

WRINGE, A., CATALDO, F., STEVENSON, N. \& FAKOYA, A. 2010. Delivering comprehensive home-based care programmes for HIV: A review of lessons learned and challenges ahead in the era of antiretroviral therapy. Health Policy \& Planning, 25(5):1-11.

ZAHED, S., EMAMI, M., BAZARGAN-HEJAZI, S., ESLAMI, A.A., BAREKATAIN, M. \& ZAMANI-ALAVIJEH, F. 2019. What motivates informal caregivers of people with dementia (PWD): A qualitative study. BMC Palliative Care, 18(105):1-7. 